\title{
A geografia americana no contexto das diferenciações de áreas de Richard Hartshorne
}

Uma leitura histórico-epistemológica

American geography in the context of Richard Hartshorne's areal

differentiations: A historical-epistemological reading

Geografía estadounidense en el contexto de las diferenciaciones de areas de Richard Hartshorne: Una lectura histórico-epistemológica

La géographie américaine dans le contexte des différenciations de areas de Richard Hartshorne: Une lecture historico-épistémologique

\section{Rodrigo Dutra-Gomes and Antônio Carlos Vitte}

\section{OpenEdition}

\section{Journals}

Electronic version

URL: https://journals.openedition.org/terrabrasilis/5085

DOI: 10.4000/terrabrasilis. 5085

ISSN: 2316-7793

Publisher

Rede Brasileira de História da Geografia e Geografia Histórica

Electronic reference

Rodrigo Dutra-Gomes and Antônio Carlos Vitte, "A geografia americana no contexto das diferenciações de áreas de Richard Hartshorne", Terra Brasilis [Online], 12 | 2019, Online since 29 December 2019, connection on 05 December 2022. URL: http://journals.openedition.org/terrabrasilis/ 5085 ; DOI: https://doi.org/10.4000/terrabrasilis. 5085

This text was automatically generated on 5 December 2022

All rights reserved 


\title{
A geografia americana no contexto das diferenciações de áreas de Richard Hartshorne
}

\author{
Uma leitura histórico-epistemológica \\ American geography in the context of Richard Hartshorne's areal \\ differentiations: A historical-epistemological reading \\ Geografía estadounidense en el contexto de las diferenciaciones de areas de \\ Richard Hartshorne: Una lectura histórico-epistemológica \\ La géographie américaine dans le contexte des différenciations de areas de \\ Richard Hartshorne: Une lecture historico-épistémologique
}

Rodrigo Dutra-Gomes and Antônio Carlos Vitte

\section{Introdução}

1 Como um contexto histórico de um país expressa as proposições de um autor? Essa é uma das formas de refletir sobre a epistemologia de uma disciplina, sobre as condições que influenciam a construção do conhecimento, suas teorias e práticas. Neste texto pretende-se apresentar a expressão histórica de uma proposição. Demonstrar que as proposições do geógrafo Richard Hartshorne (1899-1992), sob a referência da noção de diferenciação de áreas, no final da década de 30, expressa uma condição histórica cujo destaque das particularidades areais, arbitrariamente definidas, eram eminentes. Neste sentido, a geografia americana estava sob forte influência do emprego do que, no período, Hartshorne chamou de diferenciação de áreas. A proposta não é realizar um exame epistemológico do período ou do autor, mas sim uma descrição histórica das demandas advindas das necessidades e desafios geográficos da sociedade e das formas de se pensar e praticar a Geografia nas primeiras décadas do século XX nos Estados Unidos; e, a partir disso, demonstrar pelas proposições originais de Hartshorne a resposta e expressão de um período. Dessa forma, não se pretende apresentar as 
influências que Hartshorne exerceu sobre as teorias e os autores, mas sim como suas proposições responderam às demandas do período.

O texto se apoia em aspectos da abordagem contextual de Berdoulay (2003), trazendo à tona as ideologias de um período, bem como algumas das principais questões que envolviam a sociedade americana da época e que se reverteu em demandas para o uso da ideia de diferenciação de áreas e a produção do conhecimento regional. Nesta direção considerar-se-á, apoiado em Berdoulay (2003), que existem sistemas de pensamento em mudança, assim como há continuidade de ideias tradicionais, sem que para isso, em nível de método de leitura, haja uma radical dicotomia entre fatores internos e externos da mudança científica. Neste sentido, serão abordadas tanto a escala da sociedade, instituições e eventos, quanto a individual oriunda da própria leitura do autor. Em termos de sociedade serão examinadas mais as razões que estiveram por trás da "demanda" ou "uso" da ideia de diferenciação de áreas do que sua possível "influência" no contexto. Contudo, certos aspectos da abordagem de Berdoulay (2003) não serão aqui aprofundados, por exemplo, o "círculo de afinidades", que busca averiguar as ideologias influentes nos autores a partir dos elos entre os cientistas.

o texto está dividido em duas partes com sentidos cruzados, pois escritos em encadeamento histórico. Inicialmente, com um enfoque principalmente histórico, será apresentado o contexto de expansão da geografia americana nas universidades, e as demandas geográficas do período antes e pós-Primeira Guerra Mundial. Na segunda parte o prosseguimento histórico dá destaque à especificidade das proposições de Hartshorne, seus contextos práticos de atuação e influências teóricas até o período da Segunda Guerra Mundial.

\section{A expansão da geografia americana: contextos e demandas}

4 Pretendemos demonstrar neste tópico que, logo após uma fase de forte influência naturalista e evolucionista no final do XIX e início do XX, tanto de evolução das formas de relevo quanto de relações homem/meio, a geografia americana vem responder a uma demanda de investigação das especificidades das áreas, tanto interna ao país, dos próprios recursos naturais e humanos, quanto externa, de conhecimento do mundo. 0 início do século XX é marcado pelo globalismo, pela primeira vez a sociedade ocidental apresenta uma consciência de mundo, de conexão geográfica dos lugares. $O$ termo globalismo, neste caso, diferencia-se de globalização - esta última caracterizada pelo avanço e disseminação das tecnologias de informação no final do século XX, e suas diversas repercussões, econômicas, culturais, políticas etc. Chamamos de globalismo o que Harvey (1992) chamou de primeira fase de compressão espaço-temporal (final do XIX e início do XX). Este globalismo foi acompanhado pela primeira fase de expansão da economia e política americana no mundo, e isso veio amparado estrategicamente do aprimoramento das ciências geográficas e do conhecimento geográfico das áreas.

5 Em termos geoeconômicos, nos Estados Unidos, a expansão econômica e industrial já havia afirmado desde o século XIX um significativo interesse pelos estudos geográficos e seu ensino nas escolas e universidades. Não é à toa que o conhecimento geográfico se deu no ritmo da expansão das estradas de ferro, logo, de forma intensa, gerando uma conexão geográfica que colocava o campo da Geografia como estratégico para a 
interconexão e expansão geoeconômica do país. Neste contexto, as ideias geográficas europeias adentraram nos EUA por intermédio de autores como Louis Agassiz (1807-1883) de Harvard e Arnold Guyot (1807-1884) de Princeton em estudos de oceanografia, e Joseph Kennedy, Daniel C. Gilman (1831-1908) e Francis A. Walker (1840-1897) introduzindo os avanços e refinamento da cartografia temática. Uma das principais características da geografia americana neste período foi a ênfase nos trabalhos de campo e, por isso, do raciocínio indutivo a partir da observação, ao invés do dedutivo, advindo da teoria (McMurry, 1926; Jones, 1931; Platt, 1935). Com isso, mesmo com as influências externas de teorias como as de Lyell e Werner sobre dinâmicas e evolução das formas do terreno, os pesquisadores norte-americanos desde a metade final do século XIX eram relativamente livres para observarem as formas da superfície e os processos que as produziam sem amplas pré-concepções. Muito ligados à empiria, eles geralmente desconfiavam com respeito às interpretações advindas das teorias, acreditando muito mais nas explanações pautadas na experiência pelo raciocínio indutivo do que em pressupostos mais abstratos (James, 1972).

O próprio conceito de universidade como uma comunidade de acadêmicos, surgido na Alemanha em 1874, se difundiu e apareceu na América já em 1875. Direcionou-se, então, os esforços para a qualificação da estrutura acadêmica para a formação e treinamento de estudiosos e profissionais, no caso, geógrafos, de forma a garantir a continuação das atividades de pesquisa e reflexão em vínculo com a necessidade de conhecimento geográfico das áreas particulares. Um dos pioneiros a introduzir a nova geografia ensinada na América foi o geólogo William Morris Davis (1850-1934), apontado como instrutor de Geografia Física no departamento de geologia de Harvard em 1878. Davis é conhecido pela sua proposição sobre a evolução do modelado terrestre denominado de Ciclo da Erosão. Na geomorfologia a proposta davisiana insere-se na corrente históricoevolutiva, sob influências como as teorias darwinista, $2^{\mathrm{a}}$ lei da termodinâmica e filosofia bergsoniana, realçando o caráter histórico e evolutivo da paisagem, em contraposição às correntes dinâmico-funcionais a-históricas (timeless), como foi James Hutton, Lyell, Richthofen, Gilbert etc. Esta concepção teórico-metodológica davisiana foi uma das mais influentes na Geografia e Geomorfologia ao longo de todo o século XX, constituindo um marco definitivo na geografia americana. Isso tanto como referência epistemológica para os estudos (Abreu, 2003: 51-67) quanto, em conjunto com outros personagens, como presença política para a ampliação da geografia nas universidades americanas e como campo profissional.

7 Sob a influência de propostas como a de Davis vários autores seguiram com suas próprias proposições, adensando o arcabouço da geografia americana para os desenvolvimentos que se dariam a seguir depois das duas Grandes Guerras. Em termos de proposta de conhecimento das particularidades das áreas destacaram-se nomes como Mark Jefferson, que foi um dos primeiros a estudar a especificidade da distribuição da população e estruturas urbanas no Estado de Michigan. Isaiah Bowman, aluno de Jefferson, cujo primeiro livro é a cobertura sistemática das características físico-naturais próprias das regiões singulares dos EUA, além da participação de várias expedições de caracterização geográfica pelo Peru, Bolívia, Nordeste do Chile etc. Soma-se ainda os estudos da relação homem-meio de Ellsworth Huntington com as pesquisas sobre os efeitos climáticos na vida humana, buscando explicar as especificidades das distribuições e características das populações pelas áreas (James, 1972). 
8 Neste mesmo contexto outros autores, buscando uma abordagem integrada entre os elementos físicos e humanos, foram atraídos pela abordagem britânica de delimitação de regiões, considerando a pesquisa geográfica como essencialmente regional. John Powell, por sua vez, dividiu o território nacional norte-americano em 16 regiões. W. Joerg em 1914 revisou vinte e um mapas e desenhou, a partir deles, sua própria proposta de regionalização nacional. A expansão da industrialização e comércio no início do século fez Charles R. Dryer propor que a melhor forma de se identificar as regiões naturais era "medir" a função econômica de cada uma, chamando-as de regiões econômicas naturais (James, 1972). Tal postura utilitarista não é desvinculada da ideologia pragmatista de construção da universidade americana - sobre isso, cabe melhor esclarecer.

9 A filosofia pragmatista, e principalmente a postura prática derivada (utilitarista), influenciou as condutas das instituições de ensino e governamentais dos diversos países no século XX, principalmente no pós-Segunda Guerra. No caso americano, por ser nativa, teve influência marcante e nítida nas condutas dos geógrafos americanos e nas interpretações de Hartshorne. Neste ultimo caso não adotando como teoria ou filosofia explícita, mas carregando um sentido utilitarista e político para as definições das áreas (Hepple, 2008: 1530-1541). Emergido na metade do século XIX depois da Guerra Civil americana em figuras como Charles Peirce e Willian James, o pragmatismo havia se estabelecido como corrente dominante, inclusive popular, a partir do início do século $\mathrm{XX}$. De forma geral baseia-se no princípio da utilidade, laborabilidade e praticabilidade das ideias, propostas e políticas como critérios validos para o seu mérito de verdade. A ação prática detém prioridade sobre a doutrina metafísica e a experiência em relação aos princípios fixos absolutos. Concebe-se que as ideias retiram seus significados a partir de suas consequências e suas verdades a partir de suas verificações empíricas; e daí também a fácil conservação do caráter descritivo no período de Hartshorne, e depois de 50, experimental na geografia americana. Assim, em termos gerais, pelo pragmatismo considera-se que as ideias são fundamentalmente meios, instrumentos e planos para a ação prática.

10 A estreita associação deste movimento com as ciências naturais e sociais, que estavam obtendo significativos sucessos no período, creditou ao pragmatismo a visão filosófica que era capaz de produzir semelhante progresso para a sociedade daquela proposta pela filosofia iluminista. Esse movimento filosófico teve grande influência nos meios acadêmicos e profissionais nos Estados Unidos na primeira metade do século XX. Isso contextualiza no âmbito filosófico subjacente o sentido das condutas dos geógrafos americanos, ou seja, Hartshorne estava contextualizado nos regimentos utilitaristas da universidade como instituição ligada à construção da sociedade americana e, ele mesmo, pautado neste sentido. Lembra-se que o próprio irmão de Hartshorne, Charles Hartshorne, foi um grande filósofo do pragmatismo e professor de Richard Rorty (Hepple, 2008: 1539).

11 Tal influência, de acordo com Hepple (2008), orientou a interpretação de Hartshorne das proposições de Hettner, ou seja, não simplesmente aceitando-a. As proposições dos dois autores resultam com continuidades e descontinuidades umas em relação às outras, mas são fundamentalmente próprias. Enquanto, por exemplo, as proposições de Hettner faziam parte da construção da identidade nacionalista alemã num entendimento idealista de paisagem, a abordagem americana era de orientação funcionalista e utilitarista, entendendo a paisagem a partir dos trabalhos de Davis, e 
seguindo as demandas governamentais administrativas e políticas de gerenciamentos do território que estavam em destaque no período.

\section{As particularidades areais no contexto da Primeira Guerra Mundial: práticas e reflexões}

12 Enquanto as guerras foram uma dura carga material para a Europa, os Estados Unidos ascenderam economicamente. Do período de início da guerra até a década de 50 notouse, em reflexo, um notável aumento nas aplicações do conhecimento geográfico nas resoluções dos problemas governamentais e comerciais. Com o aumento do número de profissionais treinados, as novas gerações de jovens pesquisadores, expressaram certa impaciência com os estudos puramente acadêmicos e buscaram direcionar a investigação geográfica para aspectos relevantes dos problemas práticos públicos e privados. Este tornou-se um período tanto de amplo interesse na classificação e inventário de recursos naturais, quanto, além de mapeamentos regionais, da ampliação de trabalhos de campo e da confecção de mapas em escalas locais (James, 1972: 420-445). A identificação e caracterização das particularidades areais se tornaram as principais direções da pesquisa geográfica americana.

13 Com a explosão da Primeira Guerra, os membros da Associação de Geógrafos Americanos foram convocados pelo governo para trabalhos estratégicos. Várias comissões de oficiais geógrafos foram montadas para desvelar as especificidades das áreas em guerra, com pesquisas de construção e interpretação de mapas, reconhecimento de terrenos, características dos países, melhores posições no terreno para batalhas e emboscadas etc. Como lembra James (1972), geógrafos como J. W. Goldthwaite e Lawrence Martin foram convocados para os desenhos cartográficos sigilosos de áreas estratégicas. Nesse período Douglas W. Johnson, professor de geologia no curso de geografia da Universidade de Columbia, foi designado pela Secretaria de Guerra para estudos das estratégias de guerra e táticas no terreno. 0 professor foi enviado às frentes de batalha na Bélgica, França, Itália e Balcãs para ajudar a direcionar o movimento das tropas de março a outubro de 1918. o próprio W. M. Davis, que era um ótimo desenhista, descreveu as feições dos terrenos nas zonas de guerra com seus esboços. Todo material elaborado e publicado foi enviado (cerca de 9000 exemplares) para suprir as necessidades dos oficiais das infantarias nas frentes de batalha e para o deslocamento das tropas. Durante o confronto muitos geógrafos também ajudaram nos postos de civis em várias agências de guerra e realizaram estudos sobre a logística de distribuição de utilitários alimentares e médicos para a população e tropas.

14 Em setembro de 1917, o presidente americano Thomas Wilson, requereu a organização e preparação da mais completa coleção de informações sobre as características dos países europeus para o uso na Conferência de Paz em Paris. Sob a direção do presidente da Academia de Nova York S. E. Mezes foram recrutados cerca de 150 pesquisadores, incluindo historiadores, economistas, jornalista, geógrafos e outros que tivessem conhecimentos específicos das áreas envolvidas (James, 1972: 430). Este estudo, denominado de "O Inquérito", teve como foco principal a Europa, incluindo aspectos como: 1) sua história política e diplomacia, leis internacionais; 2) interpretações geográficas de problemas territoriais limítrofes com respeito aos recursos naturais, como água e minérios; 3 ) as interconexões por meio de zonas fronteiriças, economia e geografia econômica, fisiografia e estratégias para se traçar os limites territoriais. A 
maior parte do trabalho era no campo da cartografia com a construção de mapas em escalas locais e regionais, mostrando os limites políticos antes da Guerra, a rede de drenagem local, estradas e ferrovias, cidades e pontes. Para locais de importância crítica eram elaborados blocos diagramas e mapas onde eram plotadas informações sobre a densidade da população, composição étnica, agricultura, centros industriais, recursos minerais, além de outras necessidades. Logo após o Armistício (4 de dezembro de 1918) todo esse material do Inquérito foi enviado à Paris. Isaiah Bowman foi nomeado o Chefe Territorial da Conferência de Paz e Mark Jefferson o Chefe da Cartografia. Novos mapas foram criados para as condições do pós-guerra, e, embora os novos limites territoriais tenham sido aceitos tendo como base as discussões políticas, as recomendações dos especialistas, de forma geral, eram quase sempre seguidas (James, 1972: 427-433).

A profunda depressão econômica do pós-guerra foi seguida, nos Estados Unidos, de uma fase de prosperidade na década de 20 . No período, a sociedade americana foi a primeira sociedade de consumo de massa, com todas as suas virtudes e defeitos, trinta anos antes que os outros países atingissem esse nível. É interessante notar que durante um longo período os EUA já vinham desfrutando de alimentos com baixo custo, relativa escassez de mão-de-obra, tornando constante a oferta de empregos e amplo mercado consumidor. A diferença básica a partir da década de 20 é que os principais produtos de consumo eram diferentes dos anteriores, já sendo, em parte, os mesmos produtos consumidos pelo mundo na década de 70 . Com a implantação do sistema fordista de produção e montagem, certos produtos como rádios, eletrodomésticos, além dos automóveis, começaram a ser produzidos em grande escala e baixos preços. A demanda produtiva de produtos como os automóveis fomentou a demanda de produtos complementares como pneumáticos, metalurgia etc. Os níveis de venda se mantiveram regulares pela ampliação da propaganda e publicidade em rádios. De acordo com Adams (1979: 257) naquela época nenhum outro país, nem remotamente, conseguiria alcançar esta situação econômica. Os europeus observavam a expansão americana com uma mistura de incredulidade, admiração e inveja. Assim, o sentido de intensificação da compressão da experiência espaço-temporal em direção à globalização do final do século (Harvey, 1992) foi inicialmente experienciada neste país. Em nenhum outro país do período o sentido da universalização do tempo e esvaziamento do espaço (Giddens, 1991), pela expansão do capitalismo, seguiu tanto o seu sentido prático caracterizando, também, o forte sentido pragmático da conduta americana. Num movimento antagônico e complementar, o sentido de esvaziamento do espaço para a expansão do capital novamente requereu a necessidade de se conhecer as particularidades das áreas a serem exploradas, como forma mesmo de adequadamente favorecer essa expansão.

De acordo com James (1972) este foi um período de intensos trabalhos de inventários de recursos, classificação de áreas e formas de uso do terreno pela geografia americana. Vários métodos de classificação, bem como, planos de gestão foram propostos. Envolviam o engajamento de órgãos públicos como Comitê Nacional de Planejamento de Recursos, Departamentos Regionais de Estudos de Planejamento, Comitê de Recursos Hídricos etc. Os métodos e práticas de campo ganharam aliados técnicos como as fotografias aéreas na década de 30 , possibilitando, por exemplo, no plano de mapeamento, a experimentação de diferentes escalas para a representação, de acordo 
com a complexidade do quadro natural e humano e dos interesses de utilização econômicas.

17 Condizentes com a expansão internacionalista da política e economia, esses inventários não eram somente do território nacional, mas de várias regiões do mundo. Cita-se, por exemplo, em contexto regional, a elaboração do mapa ao milionésimo da América Hispânica liderada por Isaiah Bowman. A experiência e trabalhos de Bowman no Peru, Guatemala e Honduras clarificaram o problema da falta de informações a respeito destas áreas, incentivando o mapeamento da América Latina como um todo. Bowman em 1928 publica um levantamento do quadro histórico-geográfico de 34 países - sendo a maioria europeus, incluindo Palestina, Estados Unidos e América Latina (Bowman, 1928). problemas práticos relacionados às formas de uso e gestão da superfície e recursos - o que foi reafirmado pelos planos do New Deal, conforme será discutido a seguir. Havia-se percebido que além do reconhecimento das informações sobre os recursos disponíveis era também necessário elaborar planos de gestão com o objetivo de evitar a degradação predatória e insustentável, já notável em certas regiões norte-americanas no período. Uma das pretensões era fornecer diretrizes para que os interesses privados de uso do solo não viessem a degradar os recursos. Em termos históricos, os esforços de classificação das áreas e usos potenciais já vinham sendo feitos desde o período da independência dos Estados Unidos quando ocorreu a necessidade de se expandir as informações dos recursos do Oeste, mas nas décadas de 20 e 30 do XX a necessidade era aperfeiçoar o uso econômico com respeito à quantidade de área e de produtos produzidos, sem que para isso os recursos naturais fossem degradados. Um dos trabalhos conhecidos é o estudo realizado em Michigan com a elaboração de classificações e a fixação de classes potenciais de uso econômico das áreas, cujos resultados incentivaram a realização de planos de gerenciamento para as regiões vizinhas na década de 30 (James, 1972).

Nesta movimentada situação pós-Primeira Guerra Mundial de trabalhos práticos que destacavam as particularidades areais gerou-se uma expansão dos estudos regionais, bem como, posteriormente um período de mudanças conceituais advinda da variedade de ideias surgidas experimentalmente. Tais mudanças vieram justamente das críticas advindas das várias aplicações dos estudos regionais. A expansão dos estudos regionais foi percebida por Rugg (1981) ao examinar os títulos das dissertações americanas de 1925 a 1946. O autor observou que a maioria (numericamente) dos trabalhos destacavam a temática regional. No contexto das disputas ambientalistas e possibilistas, muitos dos estudos regionais do período carregavam ambas perspectivas e enfatizavam as determinações e respostas humanas ao ambiente. A partir de 1930 o estudo de uso e gerenciamento de pequenas áreas tornou-se um dos mais praticados, o que, por sua vez, ofereceu abertura para a expansão dos enfoques geopolíticos, que até 1922 eram praticamente negligenciados nos estudos regionais.

20 Essa necessidade cada vez mais presente de intervenção nas áreas acabou desestimulando os conceitos ligados a controles físicos e respostas humanas como pregados pelo determinismo ambientalista, e uma vigorosa competição para novas abordagens para o inquérito geográfico. De forma geral, isso configurou, por um lado, em atitudes ligadas ao ajustamento do homem às condições físicas e ambiente biótico, sendo descrito a partir da Ecologia Humana, representado por Harlan Barrows em 1923, 
e, por outro lado, o estudo da identificação e explanação das diferenças observáveis entre os lugares pela superfície da Terra - tais estudos se identificam sobre o termo geral de "corologia", ou o estudo dos lugares e regiões. Apesar de ambas terem aplicabilidade prática para fins estratégicos em geral, essa disputa epistemológica não trouxe para a Geografia o prestígio que ela havia conquistado na segunda metade do século XIX. Barrows (1923), por exemplo, destacou a necessidade de um conceito organizador que penetrasse a geografia para garantir sua perspectiva distinta de tratamento da realidade. Para o autor, no período, tanto as abordagens ligadas às causas da distribuição dos fenômenos da superfície, quanto as ligadas à tarefa de descrição explicativa das regiões fracassavam nesta pretensão, advogando então, que, nesta tarefa, o problema da ecologia humana poderia ter influência revitalizadora e unificadora.

21 Assim, em termos teóricos, depois de uma fase de rápido crescimento, a disciplina se estabiliza, hesitando entre uma concepção regional, análises da relação entre o homem e meio, e os presentes estudos das paisagens. A perda de uma hegemonia teórica (num contexto de questionamento da racionalidade positivista), aliado à crescente diversificação e especialização dos diversos campos do conhecimento, trouxe dificuldades e contradições para a Geografia nas primeiras décadas do século XX. A busca por reformulações que substituíssem a pretensa racionalidade universalista do positivismo foi acompanhada pelo próprio questionamento da ciência geográfica como campo "unitário" e singular do conhecimento. A crescente especialização e diversificação dos campos científicos começaram a apresentar delineamentos cognitivos que tendiam claramente a ocupar os espaços que anteriormente se encontravam integrados ao saber geográfico. As próprias geografias "humanas e físicas" se constituíam e se afirmavam pelas especializações, acabando por mostrar as infinitas especificidades e amplitudes dos distintos horizontes. As dificuldades em the dar com estas diferentes lógicas, frequentemente redutoras pela justaposição de entendimentos não facilmente conexos, resultaram numa generalizada confusão para o trato das dimensões humanas e naturais, subjetivas e objetivas que era então afirmada pela "síntese geográfica".

22 As noções de região e paisagem não ficaram isentas de problemas. As carências de uma definição rigorosa e operativa para elas, acabaram por proliferar problemas em torno de diferentes conceptualizações e promoveram críticas mútuas acerca das indefinições e ambiguidades. Isso gerou a incomunicabilidade entre as diversas proposições e temáticas. Em decorrência houve a propagação de interpretações subjetivas e heterogêneas, acompanhado de um sentimento que se traduzia em críticas sobre os baixos níveis de coerência metodológica e conceitual que, muitas vezes, não asseguravam um acordo consistente para o tratamento dos problemas e realização da síntese geográfica (Mendonza et. al, 1988: 92).

23 Assim, junto com a intensificação dos trabalhos práticos em contexto, ligados a uma postura mais pragmatista, política-gerencial e econômica de leitura das áreas, cujo caráter funcional não respeitava limites objetivos e orgânicos, nem distinções entre humano-físico, houve concomitantemente questionamentos epistemológicos, que, retroativamente, podem ser vistos como respondendo à influência do período. As antigas certezas geográfico-positivistas deram lugar a uma certa insegurança e desacordo entre as diferentes perspectivas que animavam a crescente diversidade e heterogeneidade conceitual e metodológica na geografia na primeira metade do século 
XX. Somada à crescente especialização no âmbito científico derivaram-se muitas das dificuldades e questionamentos que movimentaram, em resposta, discussões e proposições que se esforçaram para salvaguardar a objetividade, unidade teórica, metodológica e identidade da Geografia junto aos outros campos. Uma das destacadas proposições deste projeto de reconciliação do saber geográfico com sua tradição generalista, unitária e singular, ainda em torno do conceito de região, foi realizada pelo americano Richard Hartshorne.

\section{As diferenciações de áreas de Hartshorne no contexto da Crise de 30 e Segunda Guerra Mundial}

epistemológicas internas, Hartshorne, no final da década de 20 e ao longo da década 30 , desenvolveu estudos que lhe deram ampla visão do campo geográfico - incluindo estudos de regiões agrícolas, transporte e desenvolvimento urbano, climatologia, fatores pertinentes para a localização de industrias de manufaturas, distribuição racial nos Estados Unidos e reflexões conceituais em geografia política. Contextualiza-se que os estudos de Hartshorne insere-se no período de promulgação do primeiro (1933-1935) e segundo (1935-1941) New Deal, em resposta à grande depressão econômica a partir de 1929. No primeiro caso, as medidas envolvidas no pacote visavam fornecer meios de desenvolvimento da agricultura e reorganização da indústria privada, além da realização de obras públicas urbanas e construção de estradas. No segundo plano o pacote de medidas deu maior ênfase ao fortalecimento da seguridade social, criando novos organismos de planificação regional, cujos trabalhos que envolviam geógrafos detinham demanda.

Neste período a Geografia, pela cartografia, tornou-se uma ferramenta de marketing geopolítico. Serviu principalmente como instrumento de legitimação ideológica das estratégias geopolíticas norte-americanas, um poder que ajudava a afirmar, em solo nacional, as geopolíticas internas e externas mais agressivas para responder à crise e à geopolítica do pós-guerra. As representações espaciais foram usadas como mecanismos de propaganda, seja para ajudar no reordenamento espacial pela expansão industrial e vender o padrão de paisagem a ser adotada (massificada), seja para sugerir a superioridade americana em relação aos outros países (Schulten, 2001). Como destaca Schulten (2001) essa mass market cartography se esforçou para desenvolver um estilo homogêneo de produção de mapas que, em termos utilitários, se vinculava muito mais à obtenção de lucro das indústrias e afirmação de mecanismos ideológicos do que para com valores estéticos e de representação fidedigna das formas do mundo. A Geografia, e a representação geográfica, desempenhava um sentido utilitarista que respondia à demanda ideológica do período.

Neste contexto, sob referências historicistas, Hartshorne tanto dá um sentido funcionalista e político para a definição de regiões quanto busca tratar epistemologicamente as indefinições e ambiguidades conceituais da disciplina, como a dupla dicotomia entre geografia geral-sistemática e regional-singular e das temáticas físicos-naturais e humanos. 0 historicismo foi utilizado como método para Hartshorne realizar sua análise sobre o campo da Geografia. $\mathrm{O}$ historicismo, consolidado em autores como W. Dilthey, acentuou o papel do homem na natureza e na sociedade, com a defesa da liberdade de suas escolhas em oposição às forças impositivas dos viéses dos controles 
ambientais. O historicismo declarou a impossibilidade de se aplicar os métodos das ciências naturais nas ciências humanas. Isso, contudo, não excluiu a ideia de obtenção de um conhecimento objetivo e rigoroso acerca dos fenômenos humanos, indo, porém, à procura de meios alternativos para o seu estudo. Enquanto método o historicismo envolve procedimentos rigorosamente testados, entretanto mais compreensivos que explicativos, e que melhor se adapte à busca por respostas à consciência histórica da percepção e experiência humana do mundo.

Sob este apoio historicista Hartshorne inicia sua abordagem teórica pela valoração e resgate dos ensinamentos dos autores alemães clássicos via Kant-Humboldt e Hettner procurando colocá-los em conformidade com o método científico vigente justamente para afastar as inseguranças metodológicas presentes. A partir de um exame crítico sobre a evolução da ciência geográfica, em resgate de suas tradições, buscou afirmar o caráter regional e singular do método corológico da geografia em conformidade com a tradição metodológica empírico-indutiva.

O funcionalismo que Hartshorne utilizou foi decorrente do aparecimento de uma nova fase do positivismo evolucionista atuando nas ciências humanas nos EUA. Apareceu como reação às interpretações lineares e universalizantes do evolucionismo, com o abandono de sua "pseudo-história" evolutiva direcionadora dos fenômenos, considerada pelos críticos como uma hipótese que não poderia ser demonstrada. Negando a concepção unilinear da história, o funcionalismo reconheceu que havia processos funcionalmente diferenciados que constituíam unidades heterogêneas de desenvolvimentos evolutivos. Postulou uma explicação com base na pluralidade das linhas de evolução, onde a soma dos fatores étnicos, econômicos, ambientais e históricos explicariam as diferentes áreas geográficas, através de diferentes fatores alternados. Subordinou-se a história ao estudo concreto dos casos particulares das sociedades consideradas, entendendo que cada uma dessas sociedades se comportaria como uma unidade funcional relativamente autônoma. A realidade seria considerada um conjunto articulado de unidades - históricas, sociais, espaciais - claramente diferenciadas e com relativa autonomia funcional e comportamentos específicos e desiguais. Aplicada ao conhecimento geográfico esta perspectiva postulou um funcionalismo universal para os componentes da superfície terrestre, com funções mútuas e convergentes (Bray, 1977: 30; Ferreira \& Simões, 1986: 74; Mendoza et al, 1988: 62). Esta abordagem chega em Hartshorne em sua leitura sobre o Estado, que foi descrita por Sanguin (1977):

A partir de ideias sobre os conceitos e métodos da geografia política esboçados em 1935. Hartshorne elabora em 1950 a abordagem funcional em geografia política, cujo tema central é o funcionalismo do Estado. Cada Estado tem diferenças e similitudes regionais; as diferenças tendem a fragmentar o Estado, enquanto que as semelhanças tendem a fortalecê-lo. Há, portanto, dentro de um Estado, uma contínua oposição entre as forças centrífugas e as forças centrípetas. Se o Estado pode sobreviver a esta oposição é porque ele possui uma razão de ser ("state idea"), um sentido nacional e um núcleo central ("core area") suficientemente fortes para superar esta posição estrutural e manter sua coesão. Assim, a abordagem funcional permite avaliar a viabilidade do Estado. (Sanguin, 1977: 10-11)

O exame historicista e proposta funcionalista de Hartshorne (1939: 173-412; 1939b: 413-648) foi amplamente aceito como uma autoridade, uma leitura exemplar sobre os pontos de vista dos autores clássicos, como produto de um laborioso e cuidadoso estudo. Com base nas tradições destacadas a geografia reconheceu-se como a ciência que estudava as "diferenciações de áreas". Hartshorne, por meio da análise da evolução 
histórica da geografia, principalmente via Kant, Humboldt e Hettner, retomou as tradições alemãs e baseou-se em Kant para justificar a geografia científica como detentora de um procedimento metodológico próprio. Destacou as conexões causais dos fenômenos e o sentido de sistematicidade e objetividade dos procedimentos herdados a partir de Newton-Kant na síntese primordial que desencadeou o conhecimento geográfico moderno. A aplicação atualizada desta estrutura clássica asseguraria o status analítico das "descrições geográficas" orientando-as para generalizações e conceptualizações legislativas próprias das ciências, sem, contudo, perder o especial foco sobre as particularidades das áreas. Com base na avaliação de sua conduta histórica a geografia foi considerada como referindo-se aos "estudos das áreas de acordo com suas diferentes relações de causalidades - a ciência das diferenciações areais da superfície da terra" (Hartshorne, 1939: 274).

Por "área" Hartshorne está reconhecendo a existência de uma arbitrariedade presente no conceito de região, expressando uma certa ruptura ou descompromisso com o sentido orgânico desta última (herança alemã e francesa). Assim, apesar de utilizar o termo região, teve ressalvas em relação ao seu emprego, preferindo usar o termo área. Sob influência neokantista de Hettner e tendência utilitarismo-funcionista americana, os recortes das divisões areais, ou regionais, não são considerados como realidades em si, mas tratados como produtos intelectuais provenientes das pretensões do pesquisador. Neste discernimento tem-se como objetivo a captação das inter-relações entre os fenômenos que sejam significantes pelos objetivos e problemáticas presentes, e que em decorrência deduz-se a integração característica da área. Essa significância pode ser captada a partir da observação entre as relações que são mais constantes e que apresentam um grau elevado de conexão entre os lugares. A ênfase torna-se com respeito aos processos e as funções dos fenômenos, e não somente de sua genêse e relações causais como tratado em Hettner. Não sendo somente importante a apreensão das combinações dos diversos fenômenos, mas também se estes fenômenos em determinado lugar podem, ou não, se relacionarem com outros fenômenos em outros lugares (Lencioni, 2003: 127-128).

31 De Hettner herdou a distinção de W. Windelband entre procedimentos nomotéticos e idiográficos, que aliás, não eram específicos da geografia. A generalidade e particularidade foram notadas como irredutíveis a todos os campos, associando-as às execuções sistemáticas-nomotéticas e regionais-idiográficas respectivamente. Mas, apesar da maioria dos geógrafos assumirem que a geografia de Hettner teve um grande impacto na de Hartshorne, Harvey e Wardenga (2006: 422-440) sustentam que não houve qualquer imposição, no sentido da Geografia alemã ser "suprema" em relação à americana. $\mathrm{Na}$ verdade, os autores observam significativas diferenças entre as proposições dos dois geógrafos, por exemplo, sobre o lugar da Geografia entre as disciplinas científicas, a importância das abordagens idiográficas e nomotéticas, as relações entre geografia sistemática e regional, e entendimentos sobre a noção de paisagem. Para os objetivos presentes as minúcias dessas diferenças não precisam ser expostas, mas apenas realçado o fato de ser errônea a impressão de que as proposições de Hettner constitui uma base fixa ao qual foram derivadas, por raciocínio lógico, as respostas hartshornianas às questões discutidas. Hartshorne sugeriu que a posição de Hettner, longe de ser uma concepção absoluta, poderia ser considerada mais como uma hipótese para ser empiricamente validada. Das diferenças que poderiam ser realçadas entre as proposições de Hartshorne e a tradição alemã está, por exemplo, o vínculo do 
primeiro numa abordagem funcionalista e pragmatista sobre as diferenciações de áreas e seus propósitos. Ambos definem o conceito de áreas e regiões em termos relacionais. Contudo, Hartshorne (1939: 391) dá maior ênfase à questão subjetiva de definição de áreas; para ele as regiões "são entidade apenas em nosso pensamento", em contraste com a noção de região enquanto substância, característica da tradição alemã e francesa.

(...) essas áreas-unidades não são objetos ou fenômenos, mas, pelo, contrário, criações da mente do pesquisador (...). (...) dessa forma, qualquer sistema de classificação e de hipóteses, nela baseado não depende da realidade, mas do que estiver presente no espírito do observador. 0 máximo que se poderia produzir, se limitaria a leis concernentes ao pensamento dos geógrafos acerca das áreas da terra (...). (Hartshorne, 1939: 169, 391)

(...) Qualquer divisão regional do mundo, que leva em conta todos os elementos relevantes não é uma verdadeira imagem da realidade, mas sim um dispositivo arbitrário do pesquisador, mais ou menos conveniente com o seu propósito - é por isso que os discernimentos diferem de pesquisador para pesquisador, dependendo de quais elementos aparecem para eles como mais significativos. (Hartshorne, 1939: 285)

Em relação ao contexto de seu próprio país, essa funcionalidade utilitarista é bem característica da filosofia pragmatista universitária e dos propósitos interventores da expansão capitalista americana do período, para a definição de áreas, nacionais e internacionais, à serem conhecidas, ocupadas, utilizadas, melhor exploradas, não degradadas, e com extração do máximo de benefícios, tanto público quanto privado. Neste sentido, em termos políticos, econômicos e administrativos, nesta última citação, quando Hartshorne se refere aos "uma decisão arbitrária do pesquisador, mais ou menos conveniente com o seu propósito" na divisão e definição das áreas, leia-se também, em termos contextuais "propósitos do Estado, multinacionais, pentágono, CIA etc".

O principal trabalho de Hartshorne onde exibe sua concepção de Geografia, o The Nature of Geography, a região é entendida como um objeto conceitual e permanece numa posição central para a geografia, representando uma individualidade definida analiticamente pela generalização a partir das irredutíveis particularidades que constituem as áreas. Em termos metodológicos continuou em consonância com o procedimento corológico de origem kantiana e método empírico-indutivo. A região seria a síntese espacial das relações naturais e humanas abordadas universalmente pela comparação entre as estruturas espaciais formadoras das diferenciações de cada área, $\mathrm{e}$ que permitiria a conciliação entre as pesquisas dessas duas formas de raciocínio. A partir do método regional as dualidades nomotético-idiográfico/sistemático-regional se dissolveriam num certa complementaridade que se elevaria em degraus para a formulação de leis universais. Hartshorne (1978: 71-74) declara como falsa a divisão entre Geografia Humana e Física, e errônea a ideia de que a geografia seria uma ciência de ponte entre estes domínios, uma vez que, uma falsa dicotomia não necessitaria de ponte alguma. A primazia espacial no estudo geográfico colocaria os dualismos físico e humano, e nomotético e idiográfico, como secundários em relação ao que a disciplina se propõe. Ou seja, de acordo com os objetivos e problema e objetivos estudados o pesquisador se utilizará dos aspectos geográficos (físico ou humano) e procedimentos (nomotético ou idiográfico) pertinentes para desenvolvimento da investigação.

Hartshorne, na ocasião do The Nature of Geography, apresentou a ideia de diferenciações de áreas como síntese das considerações de diversos autores na caracterização da natureza do estudo da Geografia moderna. Em seu argumento sobre o conceito organiza 
as considerações feitas, via leitura neokantiana de Hettner, por Richthoffen dos pontos de vista de Humboldt e Ritter. Richthofen colocava de forma mais direta que "a geografia era o estudo da superfície da terra conforme suas diferenças, ou o estudo das diferenciações de áreas (...) em termos de suas características totais" (Hartshorne, 1978: 182). Já Hettner partia do princípio de que historicamente a “(...) matéria específica da Geografia (...) consistia no conhecimento das áreas da terra na medida em que diferiam umas das outras, com o homem sendo parte integrante da natureza de uma área"; e devido ao avanço da Ciência ampliara-se do foco nas descrições pela busca de causas no estudo das áreas (Hartshorne, 1978: 14). Em sua análise específica Hartshorne (1978: 13) buscou afastar as dúvidas e ambiguidades de interpretação do sentido da Geografia enquanto estudo das diferenciações de áreas, e concluíra que, para evitar incompreensões, tornar-se-ia mais adequado substituir o termo diferenças por variações. Nestes termos a Geografia teria “(...) por objeto proporcionar a descrição e a interpretação, de maneira precisa, ordenada e racional, do caráter variável da superfície da terra" (Hartshorne, 1978: 22); tornando a noção diferenciação de áreas uma referência conceitual para lhe dar com esse caráter variável.

Com o advento da Segunda Guerra Mundial, os serviços que requeriam geógrafos excederam o suprimento de experiência e treinamento profissional disponíveis no período. Vários professores de geografia desempenharam diferentes tipos de tarefas ligadas a Guerra, com muitas pesquisas geográficas sobre as áreas envolvidas na guerra. Geógrafos foram convocados para trabalhar em comissões oficiais, e não-oficiais, de agências de inteligência. Muitos ajudaram na preparação das informações geográficas sobre os países para planos de operações militares, ou como guia para atitudes governamentais durante a guerra. Agências como Joint Army-Navy Intelligence Studies (JANIS) tinham como tarefa a compilação e publicação de mapas detalhados da morfologia dos terrenos para fins táticos de deslocamento. Muitos geógrafos trabalharam no Office of Strategic Services (OSS), onde as informações dos países advindo do programa JANIS eram utilizados. Em setembro de 1941 Hartshorne, que, por conta da publicação do The Nature of Geography era um dos geógrafos mais conhecidos, foi chamado a Washington para chefiar a divisão de geografia da OSS. Essa divisão chefiada por Hartshorne engajou-se na Guerra pela aplicação sistemática das ciências naturais e sociais. Essa foi a agência que mais empregou geógrafos durante a Segunda Guerra - 129 ao todo (Barnes, 2006: 152).

Contudo, durante este período os geógrafos americanos encontraram uma série de dificuldades profissionais para atender as demandas da Guerra. Tarefas de inteligência como interpretar a capacidade e intenções dos inimigos sobre o avanço de suas tropas nos terrenos eram frustradas pelo pouco conhecimento dos geógrafos americanos nas características dos países da Europa, Ásia e África, em vista, da maioria ter-se focado nas regiões dos EUA e América Latina. Assim, muitos desses serviços eram realizados por especialistas de linguagem, historiadores, entre outros que tivessem algum conhecimento sobre as características das regiões em foco. Isso demonstrou o quão incompleto estava o treinamento profissional do geógrafo em seus aspectos sistemáticos. Ackerman (1945) concluiu que muitas das dificuldades na preparação dos geógrafos antes da Segunda Guerra advinha da difundida crença na dualidade e dicotomia de seu assunto, se era sistemático ou regional, se físico ou humano, se determinista ou possibilista. Essa formação dual resultava em geógrafos unilaterais com, por exemplo, especialidades nos estudos regionais, mas sem qualquer treinamento nos estudos sistemáticos, e vice-versa. Assim, a experiência do período de guerras e a 
deficiência deflagrada do treinamento e formação dos geógrafos provou que a estrutura conceitual que a Geografia se pautava ainda não havia sido amplamente entendida. Isso não quis dizer uma crítica à perspectiva regional, mas sim a defasagem nos métodos de ensino e treinamento para com as abordagens e técnicas sistemáticas, precisando ser revisados e mais bem incorporados no ensino e pesquisa. Ackerman (1945: 126) coloca:

É concebível que um viés direcionado ao método regional possa ter sido uma coisa boa para a geografia nas últimas décadas, e pode ser uma atitude que devemos continuar em nossa atividade profissional no pós-guerra. (...) Ao mesmo tempo, pode-se questionar a lucratividade em continuar com os métodos de treinamento e pesquisa que prevaleciam no passado. Penso que chegamos a um ponto em que eles não são mais valiosos em termos de originalidade e novidade, e que podemos esperar a diminuição de retornos a partir da continuidade deles.

Para Ackerman (1945: 133) tal destaque aos procedimentos sistemáticos também não significava tangenciar as pesquisas e ensino para uma hegemonia do sistemático pois acabava por perdurar a visão dualística, entre o sistemático e regional, na Geografia. Mesmo defendendo o procedimento sistemático, para o autor, o caráter monístico da Geografia seria evidente, e explicado logicamente de forma de inicial pela concepção da diferenciação de áreas de Hartshorne:

Em suma, a tese de que a geografia é um campo de unidade (e não dualidade) pode ser discutida da seguinte maneira, do ponto de vista da lógica pura: 1. Geografia é diferenciação areal. $\mathrm{O}$ objetivo final de todo estudo geográfico, seja regional ou sistemático, é a análise e descrição de toda a diferenciação geográfica da superfície terrestre. (a) É a diferenciação entre os vários elementos que compõem qualquer região, incluindo a região-mundo. (b) É a diferenciação entre totalidades das várias sub-regiões de qualquer entidade regional, cada uma composta por conjuntos de elementos variáveis ou complexos de elementos. Descrição da totalidade de todos os elementos significativos para diferenciação em suas correlações entre si, ou cada um com o todo.

O que estamos querendo destacar é a importância da região no imaginário da época advindo de uma demanda que, neste período, pós-Segunda Guerra já começava a mudar frente as novas demandas geopolíticas e geoeconômicas, exigindo novas ferramentas para lidar com as novos propósitos e problemas. Lembra-se que o período entre $1945 \mathrm{e}$ 1975 é considerado a "Idade de Ouro dos Países Industrializados" quando ocorreu a maior expansão industrial da história (Berstein \& Milza, 2007) A noção de diferenciação de áreas neste momento serviu também de apoio epistemológico para se pensar a incorporação de novas frentes possíveis de ensino e pesquisa - e que inclusive decorreria na Nova Geografia.

Neste contexto de consciência das faltas e defeitos gerou-se uma significativa mudança nas respostas da Geografia para suas aplicações, tanto para a sociedade quanto para fins militares. A experiência de alguns geógrafos na OSS e a forma como eles tiveram que se adequar e aplicar seus treinamentos (como Edward Ackerman, Chauncy Harris, Edward Ullman, entre outros protagonistas da Nova Geografia) alterou suas concepções sobre a pesquisa geográfica, ajudando a propor uma diferente atitude prática por parte da disciplina. Muitos geógrafos, depois de 50, começaram, então, a pautar suas condutas de pesquisa a partir das práticas introduzidas nas agências de guerra. As abordagens para a guerra haviam, assim, fornecido elementos para a mudança na pesquisa e pensamento geográfico, como foram as ênfase nas pesquisas multi-disciplinares, colaborações por equipes, o foco em problemas específicos a partir de grupos, e o rigor nos métodos matemáticos etc (Barnes, 2006: 163). Estes foram prelúdios para as novas posturas 
epistemológicas que ocorreriam logo a seguir na ciência geográfica, quando a Geografia - a Nova Geografia - começou a pautar muitas de suas pesquisas pela aplicação de modelos, ferramentas estatísticas e desenvolvimento de teorias.

De um contexto que requeria o conhecimento das áreas, passa-se a partir do New Deal para uma necessidade de se refuncionalizar as áreas, que pós-Segunda Guerra torna-se mais intensa para se conformar com as diretrizes da expansão industriais, na cidade e no campo. Em resposta, a Geografia, além de um conhecimento ligado ao conhecimento das particularidades das áreas, cuja região e paisagem havia hegemonicamente respondido há cerca de 100 anos (desde pelo menos Ritter), incorpora também uma leitura funcionalista, primeiro em Hartshorne, no contexto da década de 20 e 30, e depois na Nova Geografia, com o uso de teorias científicas, modelos e ferramentas estatísticas. Neste movimento, o conhecimento expressa e conduz os desenvolvimentos da sociedade, respondendo e investigando as diferentes conjunturas espaciais.

\section{Considerações Finais}

41 A concepção de Geografia como o estudo das diferenciações de áreas de Richard Hartshorne também expressa as pertinências e demandas geográficas do período em que foi elaborada. Desde meados do século XIX as necessidades e desafios geográficos $\mathrm{da}$ emergente sociedade americana vinham requerendo o conhecimento das particularidades areais para diversos fins. A interligação interna provocada pelas ferrovias conectou cada área anexada à necessidade do conhecimento de suas características físicas e humanas para a gestão e planejamento, incluindo áreas urbanas, rurais e naturais. $O$ conhecimento das particularidades areais eram eminentes e estratégicos para a administração do espaço. Estas pesquisas foram desenvolvidas pelos primeiros geógrafos americanos sob forte influência das ciências naturais, pela referência de W. M. Davis.

Em seguimento, no início do século XX as exigências trazidas pelo globalismo político e econômico e Primeira Guerra Mundial intensificou a necessidade de se conhecer as particularidades areais, agora não somente interna ao país, mas do mundo. As pesquisas americanas voltaram-se para o conhecimento das Américas e na Europa principalmente devido ao conflito. Pela intensificação dos trabalhos houve um período de novas propostas conceituais que incluíram autores como Harlan Barrows, Carl Sauer e depois Richard Hartshorne. Os problemas epistemológicos surgidos com a intensificação dos trabalhos e diversidade conceitual se expressaram em termos de divisão disciplinar e metodológica e indefinição do objeto de estudo da Geografia. Hartshorne se destacou pela leitura original ao esclarecer a complementaridade dos métodos e abordagens que, pelas aplicações positivistas, se tornavam muito discerníveis e especializados.

Por outro lado, na sociedade americana do período as definições das particularidades das áreas eram muito vinculadas à utilidade para o desenvolvimento econômico. As definições e caracterizações das áreas cumpriam diversos objetivos e utilidades, possuindo assim limites arbitrários - assim como nas proposições de Hartshorne. As regiões então poderiam ser tanto para a catalogação de recursos, planejamento de áreas, localização de indústrias, quanto para o conhecimento das geografias de outros países e regiões do mundo (econômicas, políticas, naturais, locais de batalha bélicas, deslocamento de tropas etc.) - útil ferramenta para uma sociedade com pretensões 
econômicas de expansão multinacional (que no período já despontavam com a Ford e a General Motors), e que, pela posição política, se envolvia em conflitos bélicos. Neste último caso, na Segunda Guerra Mundial a participação de Hartshorne na chefia da área de Geografia da OSS demonstrou o reconhecimento acadêmico e político que este autor desempenhou no período.

Assim, mesmo com controvérsias e críticas, sua proposta continua sendo uma das mais esclarecedoras para a ultrapassagem das dualidades e dicotomias que persistem na Geografia. Buscamos esclarecer que as leituras de Hartshorne expressam o seu período de elaboração, mas, como é de se esperar de grandes autores, isso não quer dizer que muitas de suas considerações não continuam válidas. Seguindo a abordagem contextual de Berdoulay (2003) observamos que, na verdade, houve sistemas de pensamento que mudaram, assim como houve continuidade de ideias tradicionais. Mesmo traduzindo as necessidades e desafios geográficos do início do século $\mathrm{XX}$, continua sendo uma leitura atual e primordial para o conhecimento das ambiguidades do campo. Em contexto é uma necessária leitura contemporânea cujas particularidades areais, pelos nacionalismos, novamente se destacam, e a noção de diferenciações de áreas vem novamente sendo requisitada para a leitura dos processos.

\section{BIBLIOGRAPHY}

Ackerman, Edward A. (1945). “Geographic Training, Wartime Research, and Immediate Professional Objectives". Annals of the Association of American Geographers, v. 35, Dec., n.4, pp. 121-143.

Abreu, Adilsom Avansi (2003). "A Teoria Geomorfológica e sua Edificação: Análise Crítica”. Revista Brasileira de Geomorfologia, ano 4, n. 2, pp.51-67.

Adams, Willi Paul (1979). Los Estados Unidos de América. Madrid: Siglo XXI de España Editores S. A.

Barnes, Trevor (2006). “Geographical intelligence: American geographers and research and analysis in the Office of Strategic Services 1941-1945". Journal of Historical Geography, v. 32, n. 1, pp.149-168.

Barnes, Trevor (2008). "Geography's underworld: The military-industrial complex, mathematical modelling and the quantitative revolution". Geoforum, v. 39, n. 1, pp. 03-16.

Barrows, Harlan L. (1923). “Geography as Human Ecology”. Annals of the Association of American Geographers, v. 13, n. 1, pp.1-14.

Berdoulay, Vincent (2003). “A abordagem contextual”. Espaço e Cultura, n. 16, pp. 47-53.

Berstein, Serge; Milza, Pierre (2007). História do Século XX - Vol.2 - 1945-1973, O mundo entre a guerra e a paz. São Paulo : Companhia Editora Nacional.

Bowman, Isaiah (1928). Le Monde Nouveau. Tableu Géneral de Géographie Politique Universelle. Paris: Boulevard St-Germain. 
Claval, Paul (1984). Géographie. Humanine et économique contemporaine. Paris: PUF Fondamental, Press universitaires de France.

Entrikin, Nicholas; Brunnm, Stanley (1989). Reflections on Richard Hartshorne's The nature of Geography. Washington, DC: Association of American Geographers.

Giddens, Anthony (1991). As consequências da modernidade. São Paulo: Ed. UNESP.

Hartshorne, Richard (1939). "The Nature of Geography: A Critical Survey of Current Thought in the Light of the Past". Annals of the Association of American Geographers, v. 29, n. 3. Sep., pp. 173-412. Hartshorne, Richard (1939b). "The Nature of Geography: A Critical Survey of Current Thought in the Light of the Past (Conclusion)". Annals of Association of American Geographers, V. 29, n. 4, Dec., pp. 413-658.

Hartshorne, Richard (1955). “'Excepcionalism in Geography' re-examined”. Annals of the Association of American Geographers, v. 45, n. 3, pp. 205-244.

Hartshorne, Richard (1978). Propósitos e natureza da geografia. São Paulo: Editora Hucitec. Harvey, David (1992). A condição pós-moderna. São Paulo: Edições Loyola.

Harvey, Francis; Wardenga, Ute (2006). "Richard Hartshorne's adaptation of Alfred Hettner's systems of geography”. Journal of Historical Geography, v. 32, n. 2, pp. 422-440.

Hepple, Leslie W. (2008). “Geography and the pragmatic tradition: The threefold engagement”. Geoforum, v. 39, n. 4, pp. 1530-1541.

James, Preston (1972). All Possible Wndraorlds. A history of Geographical Ideas. Indianapolis, New York: The Bobbs-Merrill Company.

Jones, Wellington (1931). "Field Mapping of Residential Areas in Metropolitan Chigago". Annals of the Association of American Geographers. v. 21, n. 4, pp. 207-214.

Lencioni, Sandra (1999). Região e Geografia. SP: EdUSP, 2. ed.

McMurry, Kenneth (1926). "Soil Mapping in Geographic Field Studies". Annals of the Association of American Geographers, v. 16, n. 2, pp.110-116.

Platt, Robert (1935). "Field Approach to Regions. Annals of the Association of American Geographers. v. 25, n. 3, pp. 153-174.

Rugg, Dean (1981). The Midwest as a Hearth Area in American Academic Geography. In: Blouet, Brian (Ed.). The Origins of Academic Geography in the United States. Nebraska: Shoe String Press, Archon Book.

Sanguin, André-Louis (1977). “A Evolução e a Renovação da Geografia Política”. Boletim Geográfico. Rio de Janeiro: IBGE, n. 252, pp. 5-35.

Schulten, Susan (2001). The geographical imagination in América, 1880-1950. Chicago: The University of Chicago Press.

\section{ABSTRACTS}

The paper presents historical conditions that influenced the geographer Richard Hartshorne. Until the decade of 40 of the XXs the American Geography was under strong influence than Hartshorne called of "areal differentiation". The proposal is realize a historical description and 
epistemological exam of the geographical needs and challenges of the American Society and the ways of thinking and practice Geography.

O texto apresenta condições históricas que influenciaram o geógrafo Richard Hartshorne. Até a década de 40 a prática da geografia americana estava sob forte influência do que Hartshorne chamou de diferenciação de áreas. A proposta é realizar uma descrição histórica e exame epistemológico das demandas advindas das necessidades e desafios geográficos da sociedade americana e das formas de se pensar e praticar a Geografia nas primeiras décadas do XX.

El artículo presenta condiciones históricas que influyeron en el geógrafo Richard Hartshorne. Hasta la década de 40 de los años XX, la geografía estadounidense estaba bajo una fuerte influencia de la que Hartshorne llamaba "diferenciación de áreas". La propuesta consiste en realizar una descripción histórica y un examen epistemológico de las necesidades y desafíos geográficos de la Sociedad Estadounidense y las formas de pensar y practicar la Geografía.

L'article présente les conditions historiques qui ont influencé le géographe Richard Hartshorne. Pour les années 40 du XXe siècle, la géographie américaine été largement influencée par ce que Hartshorne appelle "la différenciation des areas". Son objectif consiste à faire une description historique et un examen épistémologique des besoins et des défis géographiques de la société américaine ainsi que des façons de penser et de pratiquer la géographie.

\section{INDEX}

Geographical index: Estados Unidos

Chronological index: $1900-1940$

Mots-clés: Richard Hartshorne, États-Unis d'Amérique, différenciation des areas

Palabras claves: Richard Hartshorne, Estados Unidos de América, diferenciación de áreas

Palavras-chave: Richard Hartshorne, Estados Unidos da América, diferenciação de áreas

Keywords: Richard Hartshorne, United States of America, areal differentiation

\section{AUTHORS}

\section{RODRIGO DUTRA-GOMES}

Universidade Federal de Pernambuco

Departamento de Ciências Geográficas, Programa de Pós-graduação em Geografia, $\mathrm{CFCH}$, Recife. Av. Acadêmico Hélio Ramos s/n 6o andar, CDU, Recife, Pernambuco - Brasil - CEP 50740-530

E-mail: rdutragomes@gmail.com

\section{ANTÔNIO CARLOS VITTE}

Universidade Estadual de Campinas

Departamento de Geografia, Programa de Pós-Graduação em Geografia, Instituto de Geociências, Campinas, São Paulo, CEP 6152, CEP 13087-930

E-mail: acarlosvitte@uol.com.br 